\title{
Up-to-date review reporting the technological details of devices used in the management of neurogenic bladder in post spinal cord injury patients
}

\author{
Aura SPINU ${ }^{1}$, Cristina DAIA ${ }^{1,2}$, Monica HARAS ${ }^{1,2}$, Aurelian ANGHELESCU ${ }^{1,2}$, Gelu ONOSE ${ }^{1,2}$ \\ ${ }^{1}$ „Bagdasar-Arseni“ Teaching Emergency Hospital, Bucharest, Romania \\ ${ }^{2}$ "Carol Davila" University of Medicine and Pharmacy, Bucharest
}

\begin{abstract}
In the past years, a major cause of invalidity and death in post spinal cord injury (SCI) patients with neurogenic bladder (NB) was the renal failure. Since our ability to manage the dysfunction of NB has improved, the morbidity/mortality in these individuals significantly decreased.

The aims in NB management are to protect the upper and lower urinary tract and to improve the quality of life (QoL) of these individuals.

The insertion and removal of the catheter many times a day, to empty the bladder is called intermittent catheterization and it is considered the "gold standard" in the NB management.

Nowadays, there are available many types of catheters, materials and techniques: non-coated catheters, gel-coated catheters, hydrophilic catheters, glycerine based catheters.

The choice of a catheter should be made on an individual analyse, according to gender, age, level of injury, functional status, urethral sensibility, or the circumstances the IC is needed (so, a patient may need a type of catheter at home and another one outside).
\end{abstract}

Keywords: spinal cord injury, neurogenic bladder, intermittent catheterization

\section{BACKGROUND}

One of the most important sequelae in spinal cord injury $(\mathrm{SCl})$ patients is the dysfunction of the bladder, known as neurogenic bladder (NB), influencing not only the upper urinary tract function but also, these individuals quality of life (QoL). (1)

NB leads to a lot of problematic complications of the upper and lower urinary tract, in- cluding recurrent urinary tract infections, renal/ bladder calculi, hydronephrosis, vesicoureteral outflow, or renal failure. (1)

The affected patients may use in excess the healthcare system, including follow-ups, emergency visiting or hospitalization. (2)

NB in chronical patients usually becomes of incontinent type. This does not directly threaten the lives of patients, but embarrass them to have a normal social life, due to the profound 
discomfort of the leakage of the urine on linen/ skin.

In addition, the urine, usually ends up being infected - we have to mention that, whatever the circumstances surrounding the necessity of using an indwelling catheter and its persistence was higher (meaning days or weeks), the solution of continuity represented by the indwelling catheter, sets the stage for inevitable local bacterial colonization.

It is known that, incontinence is more common in chronic, sequelar patients, as a consequence of a longer period of this status of neurogenic bladder and urine is almost invariable infected (as previously stated), its contact with the skin being either propensive to determine new injuries or, in case of already existing skin lesions - including trophic type as bedsores contributes to their maintaining and worsening.

This aspect is not, however, the main target of this paper.

Instead, the NB of retention type could be a pathological condition to threaten patients life. Therefore, in the first part of this article, as a motivational background, will be reviewed the main pathophysiological stages, with prognostical comments of this complication.

\section{BLADDER PHYSIOLOGY / MICTURITION DISCONTROL PATHOPHYSIOLOGY}

The acute urinary retention is a condition resulting from the pacient's incapacity to void urine and may determine bladder wall damage (through overdistention) and/ or vesicoureteral outflow with reflex anuria and renal failure - if the bladder is not timely emptied - and even death.

Renal failure, as a consequence of the cvasipermanent vesicoureteral outflow, with renal pelvis stasis generating hydronephrosis (in time), appears more rapid in the suprasacral/ "fight" bladder - see further. (3)

The principal goal of NB management is to preserve the renal function by protecting the upper urinary tract but also, to improve as much as possible, the QoL of these patients.

It is useful to understand the neuroanatomy and the neurophysiology of this basic function, in order to better manage this harsh condition in post $\mathrm{SCl}$ patients. $(1,4)$

From an anatomical point of view, the bladder has a "body" consisting in the detrusor which is a smooth muscle - and a base - the trigon and the neck of the bladder - intercon- nected to the pelvic floor. It also has an internal, smooth sphincter and an external, striated one. (5)

The process of urination is controlled by complex mechanisms of the central nervous system and mediated by multiple neurotransmitters, and any damage at this level generates serious dysfunctions (abnormal storage and release) of the bladder. (6)

The main centre of micturition, located in rostral pons is very important and when its communication with the peripheral nerves is disrupted, the voluntary control of urination is affected. (7)

The cortical control of the pontine centre is usually maintained, excepting the situations when there is a brain lesion, too (8) - including the most unfortunate situation of concomitance: $\mathrm{SCl}$ and traumatic brain injury (TBI), within a politraumatic context.

The NB dysfunction affects the majority of $\mathrm{SCl}$ individuals (about $81 \%$ patients during the first year after the injury) and the site and the extend of the spine disruption will determine the level of bladder dysfunction. $(2,9)$ Besides, the lesions may be complete or incomplete.

As a result, the urodynamic evaluation is the following step after the neurological examination, in order to assess the type and the severity of the bladder dysfunction. (10)

Despite the fact that urodynamic examination is mandatory, the risk of urinary tract infections after this investigation is a real one: 15,79 overall incidence! (11)

In this assay, the current physician studies the filling and the voiding stages of NB and moreover, can measure the detrusor pressure, its compliance and contraction.

Bladder and sphincter pathology can be also evaluated using cystoscopy, when needed. (12)

Initially, when the lesion is severe, the bladder is non-contractile, flaccid so that the urinary volume should be less than $500 \mathrm{ml}$ for preventing the vesicoureteral outflow by overstreching the detrusor muscle. (13)

When the lesion is proximal to the sacral spinal cord, following the stage of "spinal shock", the bladder becomes hiperkinetical (spastic bladder), with a decreased storage capacity (about $300 \mathrm{ml}$ ) due to a detrusor overactivity. A detrusor - sphyncter dyssynergia (meaning a poor coordination between the bladder contraction and the sphincter relaxation) may occur. Thus, the detrusor hypertrophy determined by the bladder hipertonicity allows the vesico- 
ureteral outflow, obstruction or even both, with a potential damage of the renal function including failure, as afore mentioned.

The incontinence may be the consequence in this situation, when the detrusor pressure exceeds the urinary sphyncter pressure. (5)

If the injury involves the sacral spinal con or the cauda equina, the bladder is atone, arreactive, having a large capacity and the patients exhibit the detrusor arreflexia with the risk of incontinence, too. $(2,13)$

It is to mention that, urodynamic findings showed that there is to no important difference between the presence or absence of detrusor hypereflexia. The detrusor pressure should be kept lower than its critical threshold $(40 \mathrm{~cm}$ $\mathrm{H} 2 \mathrm{O}$ ) in order to prevent the vesicoureteral outflow. $(14,15)$

\section{MANAGEMENT OF NEUROGENIC BLADDER}

As „state of the art“ in NB treatment, including due to $\mathrm{SCl}$ patients, with partial or complete urinary retention is recommended to be the intermittent catheterization (IC), the aseptic method of IC - meaning the patients does not touch directly the one single use catheter - being preferred. (16)

Since 1972, when Lapides first introduced clean intermittent catheterisation $(\mathrm{CIC})$ in the management of NB (encompassing post $\mathrm{SCl}$ ), it has been routinely used and successfully improved the QoL of these patients and the initial ability for such an assistive endeavour, including in relation to sexual intercourse - which obviously is marked impaired/made it impossible by the presence of an indwelling catheter. (17)

Using IC, the intravesical pressure is quite appropriately controlled by regular emptying of the bladder and the blood circulation in the bladder wall is improved, resulting a decreased risk of infectious bacteria. Bacteriuria is unfortunately inevitable in patients needing long- term catheterization, but only the symptomatically ones requires treatment. (5)

A recent review regarding the risks of the $I C$, shows a prevalence of asymptomatic urinary infection of $11 \%$ and of symptomatic one of $53 \%$. (18)

IC in NB patients improves their autonomy and their sexual intimacy, compared to the use of an indwelling catheter. (5)

Initially, IC was performed with polyvinyl chloride (PVC) catheters but in 1983 it has been introduced the first hydrophilic catheter, trying to decrease the complications of this procedure.

The catheter surface properties seem to influence the complications rate, as well as the patients satisfaction.

\section{CATHETERS - TYPE AND DESIGN}

Nowadays, there are available several types of catheters, materials and techniques: noncoated catheters, gel-coated catheters, hydrophilic catheters, glycerine based catheters, all sterile, one single use, thus expressing the (desired) end of the - just - clean catheterisation.

Catheters are gender specific now, they come in a variety of sizes and are measured using French scale ( $\mathrm{Fr}$ or $\mathrm{Ch}$ ). The most common sizes are for male 10-14 Fr and for female 14-16 $\mathrm{Fr}$, but it is indicated to use the narrowest tube to minimize the urethra irritation. The end of the catheter is colour-coded to identify the size. (19)

The choice of a catheter should be made depending on gender, age, level of injury, physical independence in self-catheterization, urethral sensibility, life style/the circumstances the IC is needed (so, a patient may need a type of catheter at home and another one outside). (8)

The standard catheters are manufactured from rubber, PVC, DEHP (di-ethylhexyl phthalate), latex, silicone. This type of catheter may be washed and reused for about 1 week but, it's not recommended because of the risk of infection.

When the polyvinyl pyrrolidone (PVP) became part of the catheter surface, studies demonstrated that the friction motion was lower than the catheters coated with vaseline or xylocaine. PVP has the property to absorb and bind water, resulting a smooth and very slippery surface which lubricates the urethra when it is inserted. Thus, the friction is $90-95 \%$ lower than a plastic lubricated catheter and the risk of urethra traumatically damage is decreased. (20-22)

More advanced technology regarding chemical process succeeded to develop an isotonic catheter surface, having the same salt concentration as urine, but we are not resuming this aspect, since we've been approached it in another paper. (3)

So, the hydrophilic catheters were practically developed to reduce urethral trauma and to gain the patients compliance, being easier to use.

Thus, it is mitigating the risk for one of the long term consequence/complication of IC: de- 
velopment of strictures as emphasised in a previous work of ours. (3)

Some hydrophilic catheters require to add water but most of them are part of "all in one" devices using distilled water, i.e. impaling a very hygienic way of a lubrication in close circuit.

Another technical solution for sterile IC is the use of a PVC type, but prelubricated uniformly with water and glycerine-based formula, offering a comfortable insertion by the pharmacological properties of glycerine, in close circuit, too.

It is needful to mention, that at least for the glycerine-based coated catheters there are literature date emphasising they do not interfere with the vitality or mobility of the sperm. (23)

More advanced recent improvement, entails the adding of a ring cap to secure the tip of the catheter to be contaminated by the bacteria located in the distal urethra or by external contamination when the package is opened by hand touch and relies also on the "no-touch" system. (16) In men with $\mathrm{SCl}$, the urethra may be colonised by perineal bacteria as E Coli, Pseudomonas or Klebsiella. (24)

It is to mention, also, the NB patients (especially post $\mathrm{SCl}$ ) tend to depression, aspect related to their capacity of self-catheterization. (25)

We are presenting below, some examples of catheters used in The Neural-Muscular Rehabilitation Clinic Division of "Bagdasar Arseni“ Teaching Emergency Hospital.

\section{CONCLUSIONS}

Although, in the post-acute and chronic phase of a $\mathrm{SCl}$ patients there are many alterna-

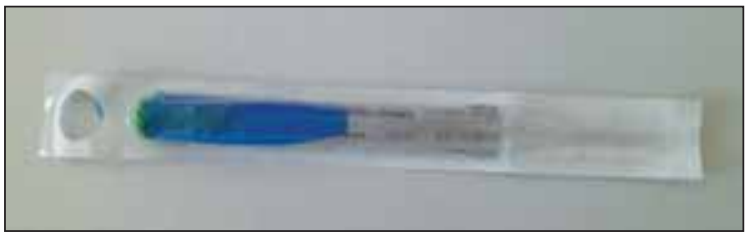

FIGURE 1. Hydrophilic catheter with lubrication in close-circuit, PVC transparent, DEHP free, used in our Clinic Division

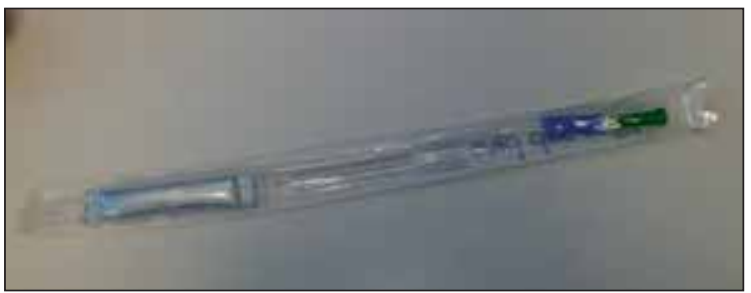

FIGURE 2. Another type of hydrophilic catheter, entailing a ring cap to secure the tip of the catheter

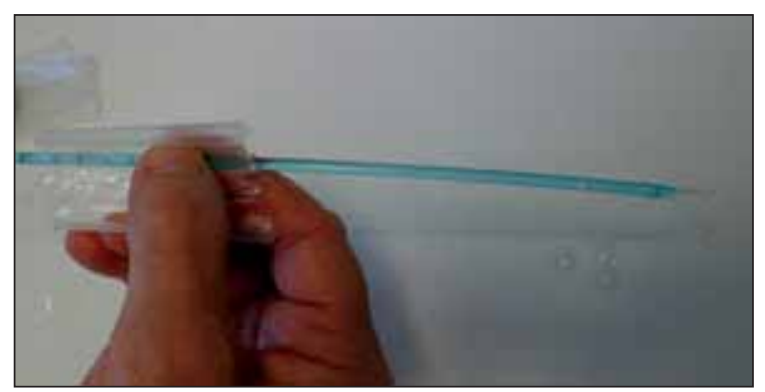

FIGURE 3. Hydrophilic catheters base on a smooth, slippery surface which lubricates the urethra when inserted, reducing the risk of urethral trauma

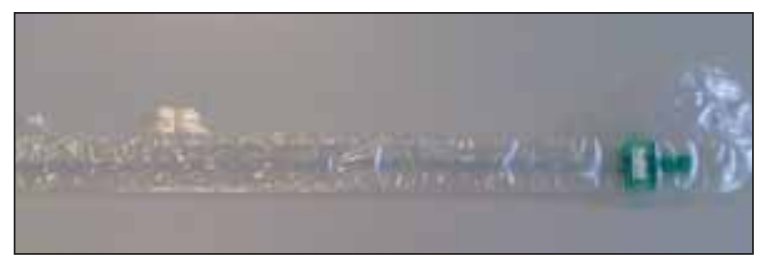

FIGURE 4. A type of prelubricated glycerine-based formula catheter, also in use in our Clinic Division

tives to drainage urine (indwelling catheters, intermittent catheters, condom sheath catheters, suprapubic catheters), sterile IC provided by lubrication in close circuit is the safest method of managing NB, preventing also better the risk of the infectious recurrence and respectively improving not only the renal function but also the QoL of these individuals. (26)

Additionally, the more and more physiological chemical content of the catheter's coatings (for instance urotonic type) contribute as well to bettering the condition of this yet, still unsatisfactory "gold standard“ in the domain. (27)

Using modern techniques in the treatment of NB, mortality through related kidney damage was reduced from $95 \%$ in the 20th century to $3 \%$. (28)

It is, however, important that, healthcare professionals to periodically instruct their patients for keeping a good compliance and a healthy urinary tract, including up dating their own training/skills, because, as it has been shown, technology - including in this field - is ever evolving. 


\section{REFERENCES}

1. Güzelküçük Ü., Demi Y., Kesikburun S., et al. Ultrasound findings of the urinary tract in patients with spinal cord injury: a study of 1005 case, Spinal Cord, 2015; 53:139-144

2. Ginsberg D. The Epidemiology and Pathophysiology of Neurogenic Bladder, The American Journal of Managed Care, 2013; 19: 191-196

3. Spinu A., Onose G., Daia C. et al. Intermittent catheterization in the management of post spinal cord injury (SCI) neurogenic bladder using new hydrophilic, with lubrication in close circuit devices - our own preliminary results, Journal of Medicine and Life, 2012; Vol V, Iss1

4. Abramson A.S., Roussan M., Feibel A. Pathophysiology of the neurogenic bladder, Bulletin of the New York Academy of Medicine, 1973; 49: No. 9

5. Dorsher P.T., McIntosh P.M. Neurogenic bladder [published online February 8, 2012]. Adv Urol. 2012; 2012:816274. doi:10.1155/2012/816274

6. Fowler C.J., Griffiths D., de Groat W.C. The neural control of micturition, Nat Rev Neurosci. 2008; 9: 453-466

7. www.uab.edu/medicine/pcp-sci

8. Benevento B.T., Sipski M. Neurogenic bladder, neurogenic bowel and sexual dysfunction in people with spinal cord injury, Physical Therapy, 2012; 82: No. 6, 601-612

9. Ku J.H. The management of neurogenic bladder and quality of life in spinal cord injury, BJU Int. 2006; 98:739-745

10. Sacomani C.A.R., Trigo-Rocha F.E., Gome C.M. et al. Effect of the trauma mechanism on the bladdersphincteric behavior after spinal cord injury, Spinal Cord (2003) 14, 12-15. doi:10.1038/sj.sc.3101354

11. Bothig R., Fiebag K., Thietje R. et al. Morbidity of urinary tract infection after urodynamic examination of hospitalized SCl patients: the impact of bladder management, Spinal Cord, 51(1): 70-73, 2013; doi:10.1238/sc.2012.107

12. http://ptjournal.apta.org/ content/82/6/601

13. Onose G., Anghelescu A. (eds.) Guideline for Good Clinical Practice in Diagnosis, Treatment and Rehabilitation of Post SCI Conditions. 2011, 78-86

14. Morita H., Sazawa A., Kanno T., Koyanag T. Long term urinary prognosis of cervical cord injury patients, Paraplegia (1994) 32, 30-35; doi:10.1038/sc.1994.6

15. Lee J.S., Koo B., Shin M.J. et al. Differences in Urodynamic Variables for Vesicoureteral Reflux Depending on the Neurogenic Bladder Type, Ann Rehabil Med. 2014 Jun; 38(3): 347-352.

16. Denys P., Aegerter P., de Seze M., Amarenco $G$. Intermittent selfcatheterization habits and opinion on aseptic VaPro catheter in Franch neurogenic bladder population, Spinal Cord (2012) 50, 853-858.

17. Hedlung H., Hjelmas K., Jonsson O., et al. Hydrophilic versus non-coated catheters for intermittent catheterization, Scand J Urol Nephrol, 2001; 35: 49-53

18. Wyndaele J.J. Complications of intermittent catheterization: their prevention and treatment. Spinal Cord. 2002; 40(10):536-541.

19. Wyndaele J.J. Intermittent catheterization: which is the optimal technique?, Spinal Cord, September 2002, Volume 40, Number 9, Pages 432-437

20. Capper V., Deane A.M., Hindmarsh J.R. Assessment of the polyvinyl pyrrolidone coated catheter, ICS, Fourteenths Annual Meeting, 1984

21. Diokno A.C., Mitchell B.A., Nash A.J., Kimbrough J.A. Patient satisfaction and the Lofric catheter for clean intermittent catheterization, The Journal of Urology, 1995; Vol 153: 349-351
22. Stansballe J., Looms D., Nielsen P.N., Tvede M. Hydrophilic coated catheter for intermittent catheterization reduce urethral micro-trauma: a prospective, randomized, participantblinded cross-over study of three different types of catheter, European Urology (2005); 48:978-983

23. Auger J., Rihaoui R., François N., Eustache F. Effect of short-term exposure to two hydrophilic-coated and one gel prelubricated urinary catheters on sperm vitality, motility and kinematics in vitro, Minerva urol nefrol 2007; 59:115-240

24. Newman D., Wilson M. Review of Intermittent Catheterization and current best practices, Urologic Nursing / January-February 2011 / Volume 31 Number 1

25. Oh S.-J., KU J.H., Paik N.-J., Yoo T. Depressive symptoms of patients using clean intermittent catheterization for neurogenic bladder secondary to spinal cord injury, Spinal Cord 2006; 44:757762. doi:10.1038/sj.sc.3101903; published online 24 January 2006

26. Weld K.J., Dmochowski R. Effect of bladder management on urological complications in spinal cord injured patients, The Journal of Urology, 2000; Vol 163: 768-772, Iss3

27. Le Breton F., Guinet A., Verollet D. et al. Éducation thérapeutique à l'autosondage (ETP-AS). Rappel des recommandations pour la mise en œuvre d'un programme d'ETP-AS. Revue de la littérature, Annals of Physical and Rehabilitation Medicine, 2012, Vol. 55:201-212, Issue 3

28. Jamil F. Towards a catheter free status in neurogenic bladder dysfunction: a review of bladder management options in spinal cord injury (SCI), http:// europepmc.org/abstract/med/11464308

\title{
Vizitați site-ul
}

\section{SOCIETĂṬII ACADEMICE dE MEdicină A FAMILIEI}

\author{
www.samf.ro
}

